\title{
DESIGUALDADES Y DISCRIMINACIONES DE LAS TRABAJADORAS SEXUALES MIGRANTES
}

\section{INEQUALITIES AND DISCRIMINATION AGAINST MIGRANT SEX WORKERS}

\author{
Tamara González Fernández*
}

RESUMEN: Ser migrante en situación administrativa irregular implica no ser considerada/o ciudadana/o, no tener derecho a tener derechos. Si además estás ocupado en alguna forma de economía informal mediante una actividad no reconocida tampoco puedes acceder a la ciudadanía a través del trabajo. Esta es la realidad las trabajadoras sexuales migrantes en España quienes sufren múltiples discriminaciones derivadas de la intersección entre las políticas de intervención abolicionistas y la política migratoria europea. Desde la epistemología feminista y la perspectiva de los derechos humanos, se recogen en este trabajo una aproximación al estatuto jurídico de estas mujeres desde sus experiencias y sus reclamaciones.

ABSTRACT: Being a migrant in an irregular administrative situation implies not being considered a citizen, not having the right to have rights. If you are also engaged in some form of informal economy through an unrecognized activity, you cannot access citizenship through work either. This is the reality of migrant sex workers in Spain who suffer multiple discriminations derived from the abolitionist interventionist policies and the European migration policy. From the feminist epistemology and the perspective of human rights, this work includes an approach to the legal status of these women from their experiences and their claims.

PALABRAS CLAVE: proyecto migratorio, prostitución, explotación sexual, trabajo sexual.

KEY WORDS: migration project, prostitution, sexual exploitation, sex work.

Fecha de recepción: 01/11/2021

Fecha de aceptación: 01/11/2021

doi: https://doi.org/10.20318/universitas.2022.6579

* Doctoranda en la Universidad de Barcelona. E-mail: gonzalezfernandeztamara@gmail.com. 


\section{1.- POLÍtICA LEgISLATIVA EN MATERIA DE PROSTITUCIÓN}

No es cierto que la prostitución no esté regulada en España, como tampoco que sea alegal. En el abanico normativo que aborda la prostitución y los aspectos relacionados con la misma encontramos normas estatales, autonómicas y locales que se pueden clasificar atendiendo a su finalidad perseguida ${ }^{1}$ como: abolicionistas ${ }^{2}$, prohibicionistas $^{3}$ y reglamentaristas ${ }^{4}$.

La norma principal que regula aspectos relacionados con la prostitución es el Código Penal. Desde una perspectiva abolicionista de la prostitución tipifica el proxenetismo en el artículo 187 castigando a quien «determine a una persona mayor de edad a ejercer 0 a mantenerse en la prostitución» siempre que medie «violencia, intimidación o engaño, o abusando de una situación de superioridad o de necesidad o vulnerabilidad de la víctima». El mismo precepto castiga con pena inferior a quien «se lucre explotando la prostitución de otra persona, aun con el consentimiento de la misma» y define las circunstancias en las que se entiende que hay explotación como aquellas en las que «la víctima se encuentre en una situación de vulnerabilidad personal o económica o se le impongan para su ejercicio condiciones gravosas, desproporcionadas o abusivas».

En este marco penal cabe la posibilidad de que una persona mayor de edad ofrezca servicios sexuales completos sin estar determinada ni explotada. Sin embargo, hay que tener en cuenta que

\footnotetext{
1 En torno a la prostitución se desarrolla un debate teórico desde distintas perspectivas que han sido analizada por numerosa literatura, una aproximación a los distintos posicionamientos puede verse <https://plato.stanford.edu/entries/feminist-sex-markets/\#Pros> acceso: 23 de noviembre de 2021.

${ }^{2}$ El abolicionismo tiene su origen a finales del S.XIX, en el ámbito del feminismo anglosajón y protestante, como respuesta a las políticas reglamentaristas que criminalizaban y estigmatizaban a las mujeres que ejercían la prostitución. Este movimiento parte de que la prostitución vulnera la dignidad de las mujeres y es violencia de género por definición, ya que es el resultado de la desigualdad y la opresión ejercida por los hombres sobre las mujeres. Aunque su discurso teórico ha ido evolucionando y podemos distinguir distintas corrientes dentro del mismo, todas consideran la prostitución como un acto coactivo que ninguna mujer realizaría si fuera libre.

${ }^{3}$ El prohibicionismo considera a las mujeres que se dedican a la prostitución como inmorales y desviadas. Hace de la prostitución un problema público y de seguridad ciudadana que ha de ser eliminado. Legalmente se caracteriza por buscar la prohibición de todas las actividades relacionadas con la actividad: vender, comprar y el proxenetismo, lo que se traduce en criminalizar tanto a las mujeres como a los clientes y las terceras personas involucradas (proxenetas y figuras afines).

${ }^{4}$ El sistema reglamentarista es el más antiguo de ellos, fue impuesto en Europa durante la segunda mitad del S. XIX y entiende la prostitución como un mal inevitable que ha de ser controlado desde la perspectiva de la salud pública. Su objetivo es sacar a las mujeres de las calles y controlar su salud. Este modelo legalmente no prohíbe la prostitución, pero implica el registro de las mujeres, el control sanitario periódico y la zonificación de la prostitución.
} 
el pasado 6 de julio de 2021 el Consejo de Ministros aprobó el proyecto de Ley Orgánica Garantía Integral de la Libertad Sexual que introducirá mediante el artículo 187 bis el siguiente literal en el Código Penal: «El que, con ánimo de lucro y de manera habitual, destine un inmueble, local o establecimiento, abierto o no al público, a favorecer la explotación sexual de la prostitución de otra persona, aun con su consentimiento, será castigado con la pena de prisión de uno a tres años, y multa de seis a dieciocho meses sin perjuicio de la clausura prevista en el artículo 194 de este código. La pena se impondrá en su mitad superior cuando la prostitución se ejerza a partir de un acto de violencia, intimidación, engaño o abuso de los descritos en el apartado 1 del artículo 187»

De esta manera se rescata la tercería locativa derogada del Código Penal de 1973 como instrumento de lucha contra el proxenetismo. Parece que asume el Ministerio de Igualdad que todas las mujeres en contextos de prostitución trabajan para terceros y no es posible que haya mujeres autogestionadas o independientes a las que también va a afectar y criminalizar esta regulación.

En segundo lugar, en la categoría de normas que podríamos clasificar como prohibicionistas encontramos a nivel local las ordenanzas municipales ${ }^{5}$ y en el ámbito estatal la Ley de Protección y Seguridad Ciudadana.

Esta última, también conocida como Ley mordaza, en su preámbulo adelante que, «se ha considerado oportuno sancionar comportamientos atentatorios a la libertad sexual de las personas, especialmente de los menores, o que perturban la convivencia ciudadana o el pacífico disfrute de las vías y espacios públicos, todos ellos bienes jurídicos cuya protección forma parte de los fines de esta Ley por su colindancia con la seguridad ciudadana».

Esto se traduce en la tipificación como infracción grave de la solicitud o aceptación de servicios sexuales. Al perseguir a los clientes podríamos pensar que se trata de una medida abolicionista pero el mismo precepto ${ }^{6}$ recoge que «los agentes de la autoridad requerirán a las personas que ofrezcan estos servicios para que se abstengan de hacerlo en dichos lugares informándoles de que la inobservancia de dicho requerimiento podría constituir una infracción por desobediencia

\footnotetext{
${ }^{5}$ Los municipios que han aprobado ordenanzas cívicas que de alguna manera han regulado aspectos de la prostitución en espacio públicos son: Barcelona en 2005, Valencia, Santander, Vic, Martorell, Mataró y Leganés en 2006; Santiago de Compostela y Lleida en 2007; Castellón, Sevilla, Huesca y Ávila en 2008; Granada y Guadalajara en 2009; Alcalá de Henares, Bilbao, Palma de Mallorca y Málaga en 2010; Badajoz en 2011; Puerto de Santa María, Zamora, Teruel y La Coruña en 2012, Valencia y Murcia en 2013. Algunas de ellas no están vigentes actualmente o, como sucede con la ordenanza cívica de Barcelona, no se aplican las normas relativas al ofrecimiento de servicios sexuales.

${ }^{6}$ Ley Orgánica 4/2015, de 30 de marzo, de protección de la seguridad ciudadana, artículo 36, apartado 11.
} 
o resistencia a la autoridad». Se da en la práctica que las trabajadoras sexuales pueden ser multadas por desobediencia a la autoridad si no cesan en la realización de un acto (el ofrecimiento de servicios sexuales) que no está prohibido en el ordenamiento jurídico español. Sin embargo, si está tipificada, «la realización o incitación a la realización de actos que atenten contra la libertad e indemnidad sexual, o ejecutar actos de exhibición obscena, cuando no constituya infracción penal». Instrumento que además de criminalizar la ocupación de las trabajadoras sexuales da a los cuerpos y fuerzas de seguridad del Estado la competencia de definir e interpretar conceptos jurídicos indeterminados atentando directamente contra el principio de seguridad jurídica regulado en el art. 9 de la Constitución española.

A nivel autonómico el Decreto 217/2002, de 1 de agosto y la Orden PRE/335/2003 de la Generalitat Catalana, regulan los locales de pública concurrencia donde se ejerce la prostitución.

De carácter reglamentarista esta norma define la prestación de servicios de naturaleza sexual como, «la actividad ejercida de manera libre e independiente por el prestador o prestadora del servicio con otras personas a cambio de una contraprestación económica bajo su responsabilidad, sin que haya vínculo de subordinación alguna respecto de la elección de la actividad».

Convirtiéndose la Comunidad Autónoma Catalana en la primera que ha definido y regulado el trabajo sexual ${ }^{7}$ como una actividad autónoma e independiente, no criminalizada, en el ejercicio de sus competencias en materia de espectáculos públicos, actividades recreativas y establecimientos de pública concurrencia. No obstante, el artículo 12 del decreto revela el objetivo principal de la norma: el control sanitario de las trabajadoras, mediante la obligación a los

\footnotetext{
7 Siguiendo el trabajo de Heim (Daniela Heim, 'PROSTITUCIÓN Y DERECHOS HUMANOS' [2011] Cuadernos Electrónicos de Filosofía del Derecho <https://ojs.uv.es/index.php/CEFD/article/view/716/472> acceso: 23 de noviembre de 2021. Utilizo la denominación «trabajo sexual» y «trabajadora sexual» para referirme a las personas que trabajan dentro de la industria del sexo. Este concepto es fruto del movimiento por los derechos de las prostitutas y presupone la aceptación del uso de las partes sexuales del cuerpo como herramienta de trabajo; reconoce la autonomía de las personas que ofrece la actividad sexual; la validez de su consentimiento; cuestiona el estigma de la prostitución y la discriminación social que comporta; reivindica el valor productivo de las tareas afectivo sexuales que la división del trabajo se las sociedades patriarcales atribuyo a las mujeres y al mismo tiempo cuestiona la ciudadanía laboral sexuada. Por tanto, son trabajadores y trabajadoras sexuales las personas que se dedican a la prostitución (entendida como servicio sexual completo) pero también todas aquellas personas que ofrecen algún servicio relacionado con la industria del sexo: alterne, web cams, streptease, línea telefónica erótica, shows en vivo y otras prácticas. Lo que, aunque en porcentaje mucho menor, incluye también a los trabajadores sexuales masculinos. Las connotaciones de este sector difieren sin embargo del femenino, tal y como ilustra perfectamente el reciente trabajo de O. Guasch y Eduardo Lizardo por lo que aquí, he optado por no incluirlo (Oscar Guasch y Eduardo Lizardo, Chaperos. Precariado y prostitución homosexual (Bellaterra 2017)).
} 
prestadores y las prestadoras de servicios sexuales a estar sujetos a controles sanitarios y a los titulares de los locales a garantizar que se someten a ellos. Es importante destacar que la imposición de controles sanitarios a las trabajadoras sexuales y no los clientes es una norma regulacionista que discrimina y estigmatiza a las trabajadoras. López y Mestre $^{8}$ recogen como los controles sanitarios obligatorios limitan el control que tienen las trabajadoras «muchos de ellos [clientes] al comprobar que están sanas, se negarán a usar preservativos, colocando a la mujer en una situación de riesgo y en gran medida desprotegida». De esta manera se reconoce el ejercicio del trabajo sexual para garantizar la protección de los clientes y los titulares de locales sin incluir los derechos laborales y sociales de las trabajadoras sexuales.

De este breve análisis del marco normativo se desprende que, aunque las políticas de intervención se nombren abolicionistas contienen instrumentos prohibicionistas y reglamentaristas que criminalizan y persiguen a las mujeres cuyo objetivo es proteger. Como señalan Ruth Mestre y Magdalena López ${ }^{9}$ en España siempre se ha regulado la prostitución con sistemas mixtos que han perjudicado en todo caso a las mujeres. El discurso abolicionista que se emite desde el feminismo institucional y alimenta el imaginario colectivo asume que el $90 \%$ las mujeres en contextos de prostitución son víctimas de trata de personas con fines de explotación sexual, por lo tanto, han sido trasladadas en contra de su voluntad mediando violencia, intimidación o engaño, o abusando de una situación de superioridad o de necesidad o de vulnerabilidad con el fin de ser explotadas sexualmente. Sin embargo, como explica Raj Redlich ${ }^{10}$, esta realidad no coincide con ni con los datos ${ }^{11} \mathrm{ni}$ con las reclamaciones que históricamente vienen realizando las trabajadoras sexuales.

\footnotetext{
${ }^{8}$ Ruth M. Mestre y Magdalena López, Trabajo sexual: reconocer derechos (Ediciones La Burbuja, 2006).

9 ibid.

10 Raj Redlich, 'Desmontando el abolicionismo del 80\%' (YouTube, 2018) < https://youtu.be/G85BXqUQ87E> acceso: 23 de noviembre de 2021.

${ }^{11}$ Este porcentaje es normalmente utilizado desde el feminismo conservador 0 abolicionista y los medios de comunicación. Sin embargo, se trata de una cifra nunca contrastada con datos o estudios científicos como demuestra Raj Redlich en su video «El mito del 80\%». Raj Redlich es trabajador sexual y activista, desde su canal de YouTube llamado «Mundo puti» hace divulgación de las reclamaciones de las trabajadoras sexuales para la descriminalización de la prostitución en España. El mito entorno a la trata de personas se da por primera vez, como señala la doctora María Luisa Maqueda (María Luisa Maqueda, Prostitución, Feminismos y Derecho Penal (Comares 2009)), a finales del S. XIX cuando a consecuencias del desarrollo que experimentó la prostitución se construyeron numerosos informes que alarmaban sobre el tráfico de mujeres destinadas a la prostitución. Como ocurre actualmente, el número de mujeres que resultó ser objeto del delito de trata fue mucho menor del reconocido, pero sirvió para que el debate en torno a la prostitución dejara de centrarse en los derechos de las prostitutas.
} 
Con objeto de aproximarme a la realidad estas mujeres vengo participando como voluntaria en el proyecto ${ }^{12}$ de atención integral a mujeres trabajadoras sexuales y atención a posibles víctimas de trata de seres humanos con fines de explotación sexual de la Asamblea de Cruz Roja de Barcelona ${ }^{13}$. En este trabajo recojo relatos obtenidos de la observación participante con mujeres que ofrecen servicios sexuales completos en la vía pública sobre sus condiciones de trabajo, su proyecto migratorio y las consecuencias que tiene en su vida las políticas de intervención en materia de prostitución.

\section{2.- LAS TRABAJADORAS SEXUALES MIGRANTES: EL PROYECTO MIGRATORIO COMO IDEAL Y LA EMIGRACIÓN COMO REALIDAD}

Según el informe de 2018 del proyecto de Creu Roja el 90,28\% de las mujeres que ofrecen servicios sexuales en Barcelona son migrantes. Entre sus relatos de cómo llegaron a España encontramos diversas historias. Por ejemplo, Virginia, ecuatoriana que llegó invitada por familiares con autorización para estancia inferior a 90 días y devino irregular al permanecer en España sin autorización de residencia y trabajo. Su compañera, Mary, llegó con su marido, quien tenía familia aquí. Entraron como turistas y permanecieron de manera irregular hasta que pudieron arreglar su documentación. Rosa es de un pueblo muy pequeño de Centro América. Cuenta que desde joven tenía claro que quería viajar y conocer otros lugares. Con 18 años viajó con una amiga a una isla del caribe donde vivió durante meses de los lujos de los turistas. Cuando terminó la temporada alta, viajaron a España invitadas por una amiga que trabajaba dentro de la industria del sexo. Lola supo desde muy joven que emigraría a España, ser transexual en su país no entraba en sus planes, llegó con una beca para estudiar y permaneció en España de manera ilegal.

También se han recogido relatos de mujeres de América Latina que entraron hace más de 15 años sin problemas de visados o autorizaciones, es el caso de Gloria que se mantuvo en España hasta que las restricciones en materia de extranjería la dejaron en situación irregular.

\footnotetext{
12 Desde el año 2009 el proyecto de Cruz Roja atiende a mujeres trabajadoras sexuales en la calle y desde 2013 en espacios cerrados (clubes, pisos y centros de masajes), su objetivo es la prevención y promoción de la salud por lo que se ofrece material profiláctico, asesoramiento y orientación sobre recursos sanitarios, sociales y jurídicos y se intenta crear una red de confianza con las mujeres. Este proyecto se desarrolla en colaboración con el Ayuntamiento de Barcelona, el Servicio de Atención Socioeducativa y la Agencia ABITS.

13 En todo caso los relatos de las trabajadoras reproducidos en este trabajo no incluyen nombres propios, lugares, fechas o cualquier otro dato identificable que pudiera perjudicar el anonimato de las mujeres que han participado en un proyecto totalmente confidencial.
} 
La entrada con autorización para estancia de viaje privado o turístico predomina entre las mujeres de América Latina y Centro América. Pero también he recopilado ejemplos de mujeres africanas con vínculos en España que les han ayudado a entrar en el país, es el caso de Marsha que vino porque su hermana vivía aquí.

Para las mujeres de Europa que proceden de países que no forman parte de la UE no es más fácil. Cristina se quedó viuda y embarazada con 18 años. Conoció a quien la traería a España en coche por mediación de unos familiares. Dejó su hija a cargo de su madre y entró como turista hace 17 años. Su compañera Sylvia llegó en autobús, una amiga de su mismo pueblo trabajaba en la calle en España y la animó a hacerlo.

Quienes no tienen conocidos en el país al que deciden emigrar que les puedan facilitar la entrada tienen que contactar con redes que les faciliten la venida y la entrada. Este es el caso de Linda ${ }^{14}$, de Norte América, mientras estudiaba en la universidad era bailarina en un club de striptease, cuando a su club llegaron chicas rusas y empezó a oír historias sobre la prostitución en España, le pidió a su empleador un pasaje para trabajar aquí en la industria del sexo. Este tenía los contactos en los clubes españoles en los que trabajaría y le facilitó la documentación de extranjería para entrar legalmente. Salir de su país y entrar en Europa por su cuenta hubiera sido imposible. Cuando llegó a España la estaba esperando en el aeropuerto el que sería su nuevo jefe. Trabajó en el mismo club durante un año, para pagar la deuda que había acumulado: billetes de avión, gestiones con extranjería y la manutención en el club durante ese año. Linda cuenta que le quitaron el pasaporte durante este periodo, podría haber huido y denunciado la perdida del pasaporte, pero le habían hecho un favor y quería pagar su deuda.

Estas historias no representan todas las posibilidades de los proyectos migratorios de las trabajadoras sexuales. Las realidades son muy diversas y se dan otras opciones de viaje y trabajo sexual ${ }^{15}$. Por

\footnotetext{
${ }^{14}$ Este nombre no aparece en cursiva al ser el utilizado por la propia trabajadora para compartir su relato en la jornada sobre trabajo sexual y migración en la librería La Caníbal.

${ }^{15}$ Laura Oso y Marcela Ulloa, investigaron los viajes de trabajadoras del sexo ecuatorianas y colombianas en Galicia y Madrid para un informe de la ONG ACSURLas Segovias, pudiendo elaborar una tipología descriptiva de las formas de acceso a España de estas mujeres: (1) migración autónoma (proceso autónomo con ayuda desinteresada de amigos y familiares); (2) participación con ánimo de lucro de individuos y entidades en el país de origen (prestamistas, agencias de viaje, etc., que cobran un alto interés por gestionar casi todo); (3) individuos y contactos en España-que con idéntico con ánimo de lucro participan de manera independiente o a través de contactos en origen (las mujeres contraen una deuda, compran su documentación a estos terceros, contactan con las mujeres en origen, reciben instrucciones y son recogidas en pisos o pensiones, o bien son trasladadas directamente al lugar de trabajo); y (4) redes organizadas o mafias implicadas en la migración de mujeres. Laura Oso y Marcela Ulloa, 'Tráfico e inmigración femenina
} 
ejemplo, otra modalidad de entrada de corta duración que se ha detectado en el último año dentro del proyecto de Cruz Roja es el de mujeres que acceden con documentación para estancia de períodos inferiores a 90 días, como turistas, pero que utilizan esta permanencia para trabajar en espacios cerrados (pisos, clubes o centros de masajes) y una vez finalizados los 3 meses regresan a su país de origen.

Sin embargo, todas las intervenciones recogidas se caracterizan por su narración en primera persona. Los proyectos migratorios de estas mujeres fueron decididos, organizados y llevados a cabo por ellas. Es importante destacar esta iniciativa para emprender un proceso migratorio que incluye actividades relacionadas con la industria del sexo porque esto desplaza el papel monolítico que tanto las instituciones como las ONGs han otorgado a las redes de tráfico. De las historias de estas mujeres se infiere que esas redes están formadas en realidad, por agentes de todo tipo: familiares, amigos, empresarios del turismo, empresarios de la industria del sexo, gestores, abogados y transportistas, entre otros. Como señala Laura de Agustín ${ }^{16}$, numerosos personajes han participado en el arreglo de los viajes de estas mujeres, el deseo de viajar nació en ellas mismas, la necesidad de hacer dinero y aceptar cualquier trabajo que aparezca en el camino, no cae en la categoría nítida de "víctima de tráfico"17. Sus vidas son mucho más complejas e interesantes de lo que tales etiquetas implican.

Las mujeres recurren a las estrategias que tienen a su alcance ya que entrar en España legalmente no es fácil ni rápido y depende en gran medida de dónde vengas ${ }^{18}$. «De acuerdo a los estatutos de las naciones (Primer mundo, pobre, en guerra, no europeo), los gobiernos deciden cómo etiquetar a la gente: emigrante, refugiados, trabajadores, visitantes, turistas, estudiantes o viajantes de negocio; de acuerdo a la clasificación que le fue otorgada, el viajero está sujeto a más o menos derechos y obligaciones» (Agustín 2005: 32).

Quienes quieren emigrar a España deben solicitar residencia para estudiar, para trabajar o para residir, lo cual exige estar previamente autorizados y solicitar visado. El primer requisito para iniciar la

desde la voz de las mujeres migrantes' en Elena Bonelli y Marcela Ulloa (coords.) Tráfico e inmigración de mujeres en España. Colombianas y ecuatoriana en los servicios domésticos y sexuales (ACSUR-Las Segovias, 2001).

16 Laura Ma Agustín 'La industria del sexo, los migrantes y la familia europea' [2005] Cuadernos Pagu <https://www.researchgate.net/journal/Cadernos-Pagu-01048333> acceso el 23 de noviembre de 2021.

17 Aquí Agustín hace referencia a tráfico traducido del concepto anglosajón «traffiking» que en la legislación española corresponde al delito de trata tipificado en el artículo 177 bis del código Penal.

18 Los requisitos exigidos para entrar en España están detallados en la página web del Ministerio de asuntos exteriores, Unión Europea y Cooperación y se recogen en Ley Orgánica 4/2000, de 11 de enero, sobre derechos y libertades de los extranjeros en España y su integración social (en Adelante LOE) y en el Reglamento que la desarrolla, aprobado por Real Decreto 557/2011, de 20 de abril (en adelante RLOE). 
tramitación del visado es contar previamente con una autorización de trabajo y residencia en España. La ley diferencia cuatro modalidades de autorización para trabajar y residir en España: por cuenta propia, por cuenta ajena, para profesionales altamente cualificados o por tiempo determinado.

La solicitud de un visado de residencia y trabajo por cuenta ajena exige cumplir los siguientes requisitos:

1.- No ser ciudadano/a de un Estado de la UE, del Espacio Económico Europeo o de Suiza, o familiar de ciudadanos de estos países a los que les sea de aplicación el régimen de ciudadano de la Unión.

2.- No encontrarse irregularmente en territorio español.

3.- Carecer de antecedentes penales en España y en sus países anteriores de residencia por delitos existentes en el ordenamiento español.

4.- No tener prohibida la entrada en España y no figurar como rechazable en el espacio territorial de países con los que España tenga firmado un convenio en tal sentido.

5.- No encontrarse, en su caso, dentro del plazo de compromiso de no retorno a España que el extranjero haya asumido al retornar voluntariamente a su país de origen.

6.- Abonar las tasas por tramitación de la autorización de residencia y la de trabajo por cuenta ajena.

7.- Que la situación nacional de empleo permita la contratación. Lo permite si:

a. La ocupación que va a desempeñar el trabajador en la empresa está incluida en el catálogo de ocupaciones de difícil cobertura que el Servicio Público de Empleo Estatal publica trimestralmente.

b. La Oficina de Extranjería competente considera que no se ha podido cubrir el puesto de trabajo a tenor del certificado que el Servicio Público de Empleo emite sobre la gestión de la oferta de empleo.

c. La autorización va dirigida a nacionales de Estados con los que España haya suscrito acuerdos internacionales (Chile y Perú).

d. Pueden acreditar la concurrencia de un supuesto recogido en el artículo 40 de la LOE.

8. - Presentar un contrato firmado por el empleador y trabajador que garantice al trabajador una actividad continuada durante el periodo de vigencia de la autorización para residir y trabajar. La fecha deberá estar condicionada al momento de eficacia de la autorización de residencia y trabajo por cuenta ajena.

9.- Las condiciones fijadas en el contrato de trabajo se deberán ajustar a las establecidas por la normativa vigente. Si el contrato fuera a tiempo parcial, la retribución deberá ser igual o superior al salario mínimo interprofesional para jornada completa y en cómputo anual. 
10.- El empleador solicitante deberá estar inscrito en el régimen del sistema de Seguridad Social y encontrarse al corriente del cumplimiento de sus obligaciones tributarias y frente a la Seguridad Social.

11.- El empleador deberá contar con medios económicos, materiales o personales suficientes para su proyecto empresarial y para hacer frente a las obligaciones asumidas en el contrato frente al trabajador.

12.- Si el empleador es una persona física deberá acreditar, una vez descontado el pago del salario convenido, el $100 \%$ del IPREM si no hay familiares a su cargo. Si la unidad familiar incluye dos miembros el $200 \%$. Si la unidad familiar incluye más de dos personas se deberá sumar a la cantidad anterior el $50 \%$ del IPREM por cada miembro adicional

13.- Poseer la capacitación y, en su caso, la cualificación profesional legalmente exigida para el ejercicio de la profesión.

Estas exigencias hacen prácticamente imposible que mujeres sin recursos económicos de países no comunitarios que están buscando emigrar a Europa puedan hacerlo de forma legal. Ante esta realidad, quienes están decididos a emigrar tienen dos opciones: entrar ilegalmente o entrar legalmente para estancia inferior a 90 días y permanecer de manera irregular con posterioridad. Situación que las somete en cualquier caso al estatuto jurídico de persona en situación administrativa irregular, eliminando cualquier posibilidad de trabajo formal y limitado las opciones a: trabajo del hogar y trabajo sexual.

\section{3.- DISCRIMINACIÓN POR CAUSA DE EXTRANJERÍA: SER MIGRANTE EN SITUACIÓN IRREGULAR}

Ya sea porque se ha entrado de manera ilegal o porque se alarga la estancia sin visado ${ }^{19}$ la única fórmula para obtener la autorización para residir y trabajar en España son los supuestos de autorizaciones de residencia por circunstancias excepcionales ${ }^{20}$.

\footnotetext{
${ }^{19}$ Aunque la estancia corta se puede prorrogar, para ello se exige que se justifiquen los medios de vida y el retorno, además, esta opción no permite obtener la residencia ni autoriza a trabajar. Los requisitos y el procedimiento se pueden consultar aquí: <http://extranjeros.mitramiss.gob.es/es/InformacionInteres/InformacionProcedimi entos/Ciudadanosnocomunitarios/hoja0 02/index.html> acceso: 23 de noviembre de 2021.

También cabe la posibilidad de solicitar autorización para residir sin permiso de trabajo cuando se prueban los medios económicos y el retorno. Los requisitos para esta modalidad se detallan en el siguiente enlace: <http://extranjeros.mitramiss.gob.es/es/InformacionInteres/InformacionProcedimi entos/Ciudadanosnocomunitarios/hoja0 02/index.html> acceso: 23 de noviembre de 2021.

20 Para los supuestos que estamos analizando, mujeres que viajan solas para buscar trabajo en España, no se aplican otras opciones de autorización a la residencia como la reagrupación familiar o las autorizaciones para investigar y estudiar.
} 
Todas estas requieren o bien la colaboración con la autoridad administrativa, policial, fiscal o judicial (a riesgo de ser sancionado por encontrarse en situación irregular), o bien haber sido víctima de un delito de violencia de género o de los delitos recogidos en los art. 311, $312,313,314,315,511.1$ y 512 (delitos contra los derechos de los trabajadores del $\mathrm{CP}$, con resolución judicial donde se declare la condición de víctima) o bien ser solicitante de asilo o persona desplazada.

La opción de regularización más accesible a las personas migrantes en situación irregular es el arraigo regulado en el artículo 31 de la LOE, y en los artículos 123 a 130 del RLOE. En concreto el arraigo laboral exige haber residido con carácter continuado en España (con prueba de empadronamiento) durante un periodo de dos años y una resolución judicial que reconozca la existencia de una relación laboral de duración no inferior a 6 meses, o alternativamente una resolución administrativa confirmatoria del acta de infracción de la Inspección de Trabajo y Seguridad Social contra la empresa que se ha beneficiado del trabajo ilegal de la víctima. El arraigo social exige además de haber residido de manera continuada al menos tres años, «contar con un contrato de trabajo firmado por el trabajador y el empresario en el momento de la solicitud para un periodo que no sea inferior a un año» (art. 124.2.b RLOE) y «tener vínculos familiares con otros extranjeros residentes 0 presentar un informe de arraigo que acredite su integración social, emitido por la Comunidad Autónoma en cuyo territorio tengan su domicilio habitual» (art.124.2.c RLOE).

No siendo el sexual un trabajo reconocido, estas opciones quedan excluidas, salvo que se reconozca la relación laboral en el ejercicio del alterne cuando el trabajo sexual se lleva a cabo en espacios cerrados ${ }^{21}$.

El arraigo social es la opción legal más buscada por las trabajadoras sexuales, en la mayoría de los casos se demuestra el arraigo realizando cursos de integración ofrecidos por los servicios de atención y acogida al inmigrante. Sin embargo, exige un contrato de trabajo o una promesa de este, y conseguir un contrato cuando realmente se está ejerciendo el trabajo sexual es difícil o ilegal.

Los datos obtenidos en el proyecto de Cruz Roja Barcelona, sobre trabajadoras sexuales en espacios cerrados señalan que en 2018 el $46,94 \%$ de las trabajadoras sexuales que ejercen su actividad en estos espacios (clubes/pisos/centros de masajes) y tiene seguimiento continuado en el proyecto están en situación administrativa irregular.

Las opciones reales de regularización que da la LOE a este colectivo de mujeres son limitadas, por lo que resulta sorprendente

\footnotetext{
${ }^{21}$ Siempre que se haya reconocido la relación laboral del alterne por los órganos judiciales. Recientemente, el Tribunal Superior de Justicia de Madrid ha reconocido la relación laboral en la sentencia dictada en el caso de la trabajadora sexual Evelyn Rochel (trabajadora sexual migrante integrante del sindicato OTRAS) contra el Club Flowers de Madrid, aunque no existía retribución.
} 
que más de la mitad de las consultadas refieran tener autorización de residencia y trabajo o nacionalidad española. La realidad es que de las 10 mujeres que han compartido su relato de migración durante la realización de esta investigación, solo dos se encuentran en situación irregular. Veamos por qué.

Virginia, Cristina y Sylvia contrataron un matrimonio. Cristina pagó 2500 euros a un hombre de etnia gitana para contraer matrimonio por la iglesia. Sylvia utilizó el mismo método. Ambas siguen casadas aunque no han vuelto a ver a los cónyuges desde el día de la celebración. El matrimonio con un ciudadano de la Unión Europa te permite acceder a la residencia mediante la obtención de la tarjeta comunitaria ${ }^{22}$. Esta situación genera consecuencias en la vida de estas mujeres: 3 años después de casarse, Sylvia tuvo un hijo con otra persona, pero debido a la presunción de paternidad contenida en el art. 116 del Código Civil no puede realizar actos legales relativos al hijo sin el consentimiento del marido oficial y presunto padre del niño. Serena obtuvo nacionalidad holandesa también al contraer matrimonio, pero este no fue contratado, se casó por amor y al separarse vino a España. Mary llegó a España estando casada con un ecuatoriano, por lo que obtuvo la residencia a través de la solicitud de arraigo social. Para justificar que contaba con un contrato de trabajo, en cada renovación de la solicitud compraba un contrato como asistenta doméstica a una familia española por el que pagó más de $2000 €$. Rosa obtuvo un contrato de trabajo con el que regular su situación gracias a un amigo que la daba de alta en la seguridad social cuando ella lo necesitaba. El coste de la seguridad social lo paga ella. Lola consiguió regularse dándose de alta como autónoma, anteriormente trabajó de manera irregular hasta que ahorró lo suficiente para poder pagar el asesoramiento legal que requiere esta opción. Aunque esto le supone un coste elevado en materia de asesoramiento legal la ha preferido a contraer matrimonio o comprar un contrato.

Por ello, ante la falta de recursos legales, consiguen regularizar su residencia a través de las estrategias que mejor se adapta a las necesidades y opciones de cada una. Todos estos medios están recogidos en la LOE como sanciones. Estar irregularmente en España supone una infracción grave (art. 53.1.a LOE). La solicitud de

22 Los requisitos que han de cumplir los cónyuges se regulan en la Directiva 2004/38/CE, del Parlamento Europeo y del Consejo, de 29 de abril de 2004, relativa al derecho de los ciudadanos de la Unión y de los miembros de sus familias a circular y residir libremente en el territorio de los Estados miembros; en el Real Decreto 240/2007, de 16 de febrero, sobre entrada, libre circulación y residencia en España de ciudadanos de los Estados miembros de la Unión Europea y de otros Estados parte en el Acuerdo sobre el Espacio Económico Europeo; y en la Orden PRE/1490/2012, de 9 de julio, por la que se dictan normas para la aplicación del artículo 7 del Real Decreto 240/2004, de 16 de febrero, sobre entrada, libre circulación y residencia en España de ciudadanos de los Estados miembros de la Unión Europea y de otros Estados parte en el Acuerdo sobre el Espacio Económico Europeo. 
residencia por arraigo exige permanencia en España durante 2 o 3 años que habrá de justificarse mediante padrón, pero también constituye infracción grave «consentir la inscripción de un extranjero en el Padrón Municipal por parte del titular de una vivienda habilitado para tal fin, cuando dicha vivienda no constituya el domicilio real del extranjero. Se incurrirá en una infracción por cada persona indebidamente inscrita» (art. 53.2.d LOE). Mary, Rosa y Marsha llegaron a España con visado de turista gracias a cartas de invitación gestionadas por familiares o conocidos que tenían en España. Estos vínculos también incurrieron en infracciones tipificadas en la LOE, ya que «promover la permanencia irregular en España de un extranjero, cuando su entrada legal haya contado con una invitación expresa del infractor y continúe a su cargo una vez transcurrido el período de tiempo permitido por su visado o autorización. Para graduar la sanción se tendrán en cuenta las circunstancias personales y familiares concurrentes» (art. 53.2.c LOE) constituye una infracción grave.

Y por supuesto, «contraer matrimonio, simular relación afectiva análoga o constituirse en representante legal de un menor, cuando dichas conductas se realicen con ánimo de lucro o con el propósito de obtener indebidamente un derecho de residencia, siempre que tales hechos no constituyan delito» (art. 53.2.b LOE) también está tipificado como infracción grave.

Pagar por un contrato de trabajo o por ser dado de alta en la seguridad social es una infracción muy grave (art. 54.1.f LOE).

Las graves están castigadas con multas de $501 €$ a $10.000 €$ y las muy graves con multas de 10.001 a $100.000 €$ (art. 55 LOE). Además, las infracciones muy graves y las graves contenidas en los art. 53.1 apartados $a, b, c, d$ y $f$, si son cometidas por un extranjero pueden ser motivo de expulsión del territorio español «previa la tramitación del correspondiente expediente administrativo y mediante la resolución motivada que valore los hechos que configuran la infracción» (art. 57 LOE). De ahí que «Solo un cambio en la legislación existente sobre inmigración que se apoyase en la residencia y no en el contrato de trabajo, podría garantizar que las mujeres obtuvieran sus papeles sin necesidad de recurrir a recursos ilegales y/o peligrosos» 23 .

El miedo a ser descubierta en situación irregular tiene como consecuencia principal que las trabajadoras sexuales migrantes no acudan a los cauces legales para gestionar ningún ámbito de sus vidas. Esto da lugar a situaciones de abuso y desamparo. Solicitar cantidades desorbitadas de dinero para obtener documentación o vender documentación falsa son algunos de los ejemplos que han vivido estas mujeres, pero la LOE no les ha dejado otra opción.

${ }^{23}$ Dolores Juliano, 'El trabajo sexual en la mira: polémicas y estereotipos' [2005] Cuadernos

<https://www.scielo.br/j/cpa/a/yf64fKYh9m5XKmLp9wxrCqp/abstract/?lang=es> acceso el 23 de noviembre de 2021. 
Lo más grave es la desprotección ante las fuerzas y cuerpos de seguridad del estado. Estar en situación irregular implica no tener acceso a la justicia por miedo a las consecuencias. Si no tienes papeles no puedes denunciar delitos distintos a los recogidos en los art. 311 a 315, 177bis, 511 o 512 del CP. Por tanto, si una trabajadora sexual migrante que sea agredida en su trabajo denuncia ante la policía una agresión sexual, se inicia un expediente sancionador por estancia irregular que puede acabar con la deportación ${ }^{24}$. Las trabajadoras sexuales normalmente no son identificadas como víctimas de delitos sexuales. Si las trabajadoras sexuales en general carecen de credibilidad, a las migrantes, además, se les está negando el acceso a la justicia:

No "tener papeles", de acuerdo con la LOE, además de exponer a la constante amenaza de expulsión (art.57), significa no tener derecho a circular libremente por territorio español (art.5), no poder ser escuchados por la Administración en los asuntos que les afecten al interesado (art.6), no poder ejercer el derecho de reunión, manifestación (art.7) y asociación (art.8), no tener acceso a educación no obligatoria (art.9), no tener derecho a trabajar por cuenta propia o ajena ni tener acceso al sistema de Seguridad Social (art.10), no tener derecho a sindicarse o afiliarse en una organización profesional, ni ejercer el derecho de huelga (art. 11), no tener acceso al sistema público de ayudas en materia de vivienda (art.13), no tener acceso a las prestaciones y servicios generales y específicos de la Seguridad Social (art.14), tampoco tener derecho a la vida familiar ya que no se permite la reagrupación (art.16 y 17), ni tener derecho a la asistencia jurídica gratuita para temas no relacionados con los procedimientos administrativos de extranjería (art. 22) (Arella, Fernández, Nicolás, Vartabedian 2004).

\section{4.- DISCRIMINACIÓN POR PRÁCTICAS SEXUALES ESTIGMATIZADAS: SER TRABAJADORA SEXUAL}

En palabras de la Sala de lo Social de la Audiencia Nacional: ${ }^{25}$ «no resulta posible con arreglo a nuestro derecho la celebración de contrato de trabajo cuyo objeto sea la prostitución por cuenta ajena ${ }^{26}$, esto es, un contrato en virtud del cual el trabajador[/a] asuma la obligación de mantener las relaciones sexuales que le indique el

\footnotetext{
24 Las agresiones sexuales no se consideran delitos de violencia de género, por lo que no están sujetos al protocolo de solicitud de residencia para las víctimas de estos delitos.

25 Sentencia 174/2018 [2018] AN Sala de lo Social.

${ }^{26}$ La opción de ejercer por cuenta propia como trabajadora sexual siendo extranjera es muy limitada y en la práctica imposible de llevar a cabo debido a los requisitos legales y económicos que se han de cumplimentar. Una aproximación a esta posibilidad la hace Gloria Poyatos en su libro Prostitución como trabajo Autónomo (Gloria Poyatos, Prostitución como trabajo autónomo (Bosch 2009)).
} 
empresario[/a], con las personas que este[/a] determine a cambio de una remuneración, y el contrato que así se celebre debe reputarse nulo». Continúa diciendo la Audiencia Nacional que «Estaríamos ante un contrato con causa ilícita por oponerse a las leyes y a la moral (art. 1.275 Código civil), que no sería susceptible de incardinarse en el seno la legislación laboral sino, en su caso, en el Código Penal (en adelante $\mathrm{CP}$ ), en la medida en que su art. 188 [actualmente art. 187] castiga "al que se lucre explotando la prostitución de otra persona, aun con el consentimiento de la misma", siguiendo así las tesis abolicionistas del Convenio para la Represión de la Trata de Personas y de la Prostitución Ajena, adoptado por la Asamblea General de Naciones Unidas en 2 de diciembre de 1949, en vigor desde el 25 de julio de $1951 \gg 27$. No contemplar el trabajo sexual como actividad laboral supone dejar al menos a $75.000^{28}$ mujeres trabajando sin ninguna garantía laboral, de las cuales 67.000 además son extranjeras, equivaldría, por ejemplo, a negar derechos laborales básicos a, la totalidad del cuerpo nacional de policía de España 29 .

La exclusión del ámbito laboral de estas mujeres impide la aplicación del art. 311 del CP, las trabajadoras sexuales sujetas a condiciones laborales abusivas no están protegidas por la ley. Lucía Fernández, en las jornadas sobre trabajo sexual organizadas por el Sindicato OTRAS el 8 de Junio de 2019, explicaba como ella (trabajadora sexual en especio cerrados) había sido víctima de abusos y explotación laboral. Comenta como en uno de sus primeros trabajos en Barcelona en un piso donde se hacen plazas ${ }^{30}$ los turnos de trabajo eran de 24 horas durante los 21 días. Durante ese tiempo permanecía en su habitación y en cualquier momento, cuando un cliente llamaba, tenía que presentarse y si era elegida ocuparse de él. Compartiendo esta experiencia, contó como la persona encargada de gestionar el piso le multaba por quedarse dormida o no cobrar a los clientes. Esta misma persona es la que impone el horario, las hace fichar cuando entran y salen del trabajo y fija las tarifas que cobran a los clientes. El artículo

\footnotetext{
$27<$ https://www.ohchr.org/sp/professionalinterest/pages/trafficinpersons.aspx>

28 Una de las pocas referencias al número de mujeres que ejercen prostitución en España la encontramos en la investigación promovida por el Instituto de la Mujer y realizada por el Equipo de Investigación Sociológica (EDIS S.A. Realidad social de las mujeres sin techo, prostitutas, ex reclusas y drogodependientas en España (Instituto de la mujer 2004)). Este informe especifica que solo se investiga el número de mujeres que ejercen la prostitución en la calle y en clubes sin incluir otras variedades de prostitución como teléfonos eróticos, internet o alto standing. Es uno de los más completos sobre prostitución a nivel nacional; a partir de datos autonómicos y diversas fuentes policiales, estiman que hay un total de 96.000 mujeres que ejercen la prostitución en clubes y 6.000 más en calle.

29 Según datos del Ministerio del Interior para el Congreso de los Diputados a 31 de mayo de 2016 había en España 65.711 policías nacionales en activo.

30 Las trabajadoras sexuales llaman «hacer plazas» a trabajar 21 días seguidos en el mismo local, apartamento o club. Los 7 restantes del mes, coincidentes con el ciclo menstrual, se descansa.
} 
311 del CP no es de aplicación al no ser las trabajadoras sexuales «trabajadoras» ni tener derechos reconocidos en disposiciones legales, convenios colectivos o contrato individual. Las personas y empresas que gestionan espacios cerrados donde se ejerce trabajo sexual abusan de la situación de indefensión creada por la legislación.

Es posible hablar, pues, de una nueva forma de violencia institucional contra las mujeres específicamente ejercida por las autoridades contra las trabajadoras sexuales, tal como se debatió en las Jornadas del 8 de Junio celebrados por OTRAS. Ninfa, trabajadora sexual transexual que ejerce en Madrid en espacios abierto, compartió como el hecho de que, además de por la naturaleza de su actividad, encontrarse en situación irregular le supuso meses de persecución policial en la Casa de Campo y dormir al menos una noche a la semana en el calabozo. Ninfa afirma que «se utiliza la LOE para acosar a las trabajadoras sexuales y el Estado utiliza la prostitución para hacer legislación de extranjería». Tras ser perseguida y acosada en la Casa de Campo se mudó a Alcalá de Henares, donde a pesar de no llegar la presión policial, fue objeto de múltiples robos que no pudo denunciar. Posteriormente el municipio de Alcalá de Henares sancionó el ofrecimiento de servicios sexuales en la vía pública con multas de $600 €$ y la obligaron a moverse por espacios aún más alejados y peligrosos. Esta persecución policial ha sido recogida en «Informe cualitativo sobre las percepciones, demandas y propuestas de las trabajadoras del sexo que contactan con la clientela en el espacio público de la ciudad de Barcelona», desarrollado en 2016 por Putas \& Alianzas ${ }^{31}$, donde se recogen las demandas de las trabajadoras sexuales de espacios abiertos. Estas, denuncian especialmente la presencia policial en zonas donde se contacta a la clientela, la imposición de multas ya sea por las conductas del artículo 39 de la ordenanza municipal de Barcelona o por el incumplimiento de las órdenes o requerimientos específicos formulados por las autoridades municipales recogidos en el artículo 79.1.d y la incautación de las ganancias obtenidas por las trabajadoras sexuales amparada en el artículo 101 de la ordenanza que permite decomisar «El dinero, frutos o productos obtenidos con la actividad infractora, los cuales quedaran bajo custodia municipal mientras sea necesario para la tramitación del procedimiento sancionador, o a falta de este, mientras perduren las circunstancias que motivaron el comiso». A consecuencia de este tratamiento, «las demandas son univocas: se pide que cese la violencia personal y social contra las trabajadoras sexuales». Otra de las solicitudes recogidas por las trabajadoras sexuales es la creación de «canales de comunicación con los cuerpos policiales para que éstos proporcionen protección efectiva a las trabajadoras sexuales» o «la posibilidad de contar con un cuerpo

31 Paula Mansilla, Informe cualitativo sobre las percepciones, demandas y propuestas de las trabajadoras del sexo que contactan con clientela en el espacio público de la ciudad de Barcelona (Putas\&alianzas, 2016). 
policial de proximidad que permitiera una interlocución más fluida con las fuerzas de seguridad, un mayor conocimiento entre trabajadoras y policía para mejorar la percepción mutua y aumentar la confianza».

El acoso y la vulneración de derechos sufridos especialmente por las trabajadoras sexuales migrantes también ha sido recogido por el estudio «Una aproximación a la vulneración de los derechos humanos de las trabajadoras sexuales en la ciudad de Barcelona» llevado a cabo por Celeste Arella, Cristina Fernández Bessa, Gemma Nicolás Lazo y Julieta Vartabedian ${ }^{32}$, en el que se incluyen relatos de trabajadoras sexuales arbitrariamente detenidas, registradas o identificadas. En este estudio se afirma que el acoso policial vulnera los derechos de seguridad jurídica e igualdad, ya que el trato policial no suele tener una legitimación normativa para llevarse a cabo y suele ser discriminatorio. Encontrarse en la calle, paseando o quieta esperando, no constituye ningún delito ni ninguna infracción administrativa. La calle, como espacio público, es para el uso de todas y de todos siempre y cuando haya respeto hacia las demás personas. El acoso policial, es pues, arbitrario e ilegitimo. [...] Este acoso policial se lleva a cabo de manera discriminatoria respecto al sexo y a la raza, dos causas especialmente mencionadas, como ya hemos expresado, por la CE. Decimos que existe discriminación respecto del sexo, porque suelen ser las mujeres o las transexuales las que son perseguidas y acosadas y no los hombres clientes (con algunas excepciones actuales). La discriminación por motivo de raza se da por el acoso específico que sufren las mujeres que visiblemente pertenecen a otras etnias. Este acoso se lleva a cabo amparándose en los controles realizados por la policía por cuestiones de extranjería.

En el estatuto jurídico de las trabajadoras sexuales también está eliminado el derecho de sindicación. Miquel Serra (abogado laboralista ponente en las jornadas del 8 de Junio de 2019 organizadas por OTRAS) explicó como la sentencia de la Audiencia Nacional en la que se anulan los estatutos del sindicato OTRAS, constituye el primer precedente en España de anulación completa de unos estatutos sindicales. El argumento principal de la sentencia es que el trabajo sexual no puede ser objeto de contrato laboral por ser contrario a la moral y al Convenio de $1949^{33}$. Es importante destacar que el convenio utilizado para negar el derecho de sindicación (derecho fundamental recogido en la sección primera del capítulo segundo del título primero de la Constitución ${ }^{34}$ ) de las trabajadoras sexuales es preconstitucional.

32 Celeste Arella y otros, Una aproximación a la vulneración de los derechos humanos de las trabajadoras sexuales (Observatori del Sistema Penal I els Drets Humans, 2006).

${ }^{33}$ Convenio para la represión de la trata de personas y de la explotación de la prostitución ajena, Naciones Unidas 1949.

${ }^{34} \mathrm{El}$ derecho de sindicación está recogido además en el Pacto Internacional de Derechos Civiles y Políticos de 1966 del que España forma parte y en la Carta de Derechos Fundamentales de la Unión Europea. 
Las trabajadoras sexuales son excluidas del acceso a la justicia penal y laboral, son sometidas a detenciones arbitrarias, violencia institucional, discriminación por razón de sexo y raza y abuso de poder. Además, no constar como personas empleadas en la sociedad laboral en la que vivimos limita gravemente las vidas de estas mujeres. Como refleja Dolores Juliano ${ }^{35}$ «En una sociedad en la que la participación en el marcado laboral remunerado es el medio principal de adquirir derechos y deberes, es decir la ciudadanía plena $[\ldots]$, el no reconocimiento de la condición de trabajo para sus actividades constituye un obstáculo importante para el disfrute de sus derechos y el desarrollo de sus potencialidades». Las trabajadoras sexuales no son consideradas ciudadanas. De esta manera se deja a este colectivo (trabajadoras migrantes especialmente vulnerables) sin garantías sociales como bajas laborales, vacaciones, acceso a la seguridad social, acceso al servicio nacional de desempleo, formación, ayudas públicas o derecho a la jubilación.

La propia condición de irregularidad que ha llevado a algunas mujeres a tomar la decisión de dedicarse al trabajo sexual tampoco les permite salir de él. No tener papales te deja fuera del servicio nacional de empleo, el acceso a cursos de formación y limita ampliamente las posibilidades de acceder a trabajos fuera de la economía informal, pese a que casi el $90 \%$ de las trabajadoras tienen estudios y más del $30 \%$ estudios secundarios.

Así pues, «El Lloc de la dona ${ }^{36}$ ofrece cursos para mujeres que quieran abandonar el trabajo sexual, pero la Administración no permite el acceso a las trabajadoras sexuales "sin papeles"»37. Acceder a los cursos de formación ofrecidos por las agencias y ONGs tampoco garantiza un futuro fuera de la precariedad. La oferta formativa (generalmente cursos de costura, cocina, limpieza y cuidados) tiene por objeto trabajos feminizados con horarios incompatibles con las cargas familiares que tienen la mayoría de las trabajadoras y con sueldos bastante inferiores a los que ofrece el mercado sexual.

Además de las consecuencias señaladas, las mujeres que son atendidas por la Cruz Roja refieren como una de las principales preocupaciones el acceso a la vivienda. La situación nacional de la vivienda es en 2021 alarmante, alquiler una vivienda en Barcelona, siempre por mediación de agencias inmobiliarias, se ha convertido en un problema de la ciudadanía en general, pero es especialmente difícil para las trabajadoras sexuales porque no pueden justificar sus ingresos, ni aportar las nóminas o los contratos de trabajo que exigen las agencias para acceder al alquiler de una vivienda completa. El 64\%

\footnotetext{
35 Ibid 13.

${ }^{36}$ El Lloc de la Dona es la Congregación de Hermanas Oblatas del Santísimo Redentor de Europa, que desde el evangelio da asistencia a mujeres que ejercen prostitución y viven situaciones de exclusión en el barrio del raval en Barcelona.

37 Ibid 16.
} 
de las trabajadoras sexuales en seguimiento en el proyecto de Cruz Roja viven en habitaciones alquiladas, la modalidad de vivienda que más ha crecido entre estas mujeres en Barcelona. El alquiler de habitaciones, normalmente mediante subarriendos no reconocidos en contratos, no ofrece ninguna garantía frente a los arrendadores y los abusos que se suelen producir en este mercado. Un problema adicional es que se les niega el empadronamiento tanto a las que viven en habitaciones alquiladas como a las que lo hacen en clubes o pisos, no pudiendo posteriormente probar la estancia continuada en España a los efectos de la autorización de residencia por arraigo ${ }^{38}$.

Otra de las limitaciones recogidas por el estudio realizado por Arella, Fernández Bessa, Nicolás y Vartabedian ${ }^{39}$ es la posibilidad de viajar al país de origen: «la situación de irregularidad impide a muchas mujeres volver a sus países de origen durante periodos de tiempo muy largos. De esta forma no pueden visitar a su familia, a sus hijos o saber exactamente cómo están las cosas que han dejado allí ya que se enfrentan a la posibilidad de que no les permitan la entrada en España, país en el que llevan varios años trabajando y viviendo, cuando quieran retornar».

Por último, no se pueden abordar las consecuencias de ser trabajadora sexual y migrante sin hacer referencia al estigma de ser «puta». Dice Dolores Juliano ${ }^{40}$, que el estigma de las trabajadoras sexuales es interiorizado antes de dedicarse al mismo, por lo que estas mujeres tienen que lidiar no solo con el estigma impuesto por el resto de la sociedad, si no por el estigma propio. La desvaloración de las mujeres que se dedican a esta actividad es la forma de control sexual desde la sociedad heteropatriarcal. La discriminación y el acoso a las trabajadoras sexuales no es más que una forma de control del comportamiento del resto de mujeres. Todas las mujeres han sido llamadas putas en algún momento de sus vidas cuando su comportamiento, su ropa, sus parejas sexuales o su independencia se ha salido de lo dictado para las mujeres en la sociedad en la que viven. Así pues, «se sitúa una opción laboral que no implica delito, en el mismo campo de estigmatización que la sociedad reserva para delincuentes y personas afectadas por la drogodependencia» 41 .

El estigma y la criminalización asociada a las trabajadoras sexuales hace que oculten su ocupación quedando excluidas de la sociedad. No comparten su realidad con sus familiares o allegados, lo cual las aísla y las invisibiliza más si cabe. Ser juzgadas hace que no acudan a los servicios de salud cercanos a su vivienda por miedo a ser descubiertas o que no sean sinceras con los médicos y médicas que las

\footnotetext{
38 Para paliarlo, el proyecto de Cruz Roja Barcelona ofrece a las trabajadoras sexuales migrantes la posibilidad de empadronarlas sin domicilio fijo.

${ }^{39}$ Ibid 16.

${ }^{40}$ Ibid 13.

41 Ibid 13.
} 
atienden, perjudicando los posibles diagnósticos. El informe ABITS 42 de 2017 recoge como «el estigma es muy elevado, y este está presente en la vida de casi todas las mujeres que consultan [el servicio de atención psicológica]», este produce sentimientos de culpabilidad, vergüenza y soledad que «afecta a la salud [...] observándose que cuando más estigma hay mayor es el riesgo de conductas adictivas». Las trabajadoras sexuales son presentadas como víctimas forzadas sin capacidad de gestión de su propia vida y desviadas de la norma y la moral. Ser trabajadora sexual implica que todos los aspectos de la vida de estas mujeres sean juzgados desde los prejuicios moralistas y paternalistas imperantes en el imaginario colectivo. Pero no se puede olvidar que este estigma se ve reforzado en el caso de las trabajadoras sexuales migrantes por la discriminación racial, haciendo que el rechazo social hacia ellas sea más fuerte.

\section{5.- A MODO DE CONCLUSIÓN}

$\mathrm{Ni}$ el relato de las mujeres migrantes en contextos de prostitución ni los datos ${ }^{43}$ confirman y justifican las políticas abolicionistas que se instrumentalizan desde el Gobierno.

La doble discriminación que padecen las trabajadoras sexuales migrantes en España es contraria a cualquier concepto de justicia social de un país materialmente democrático. La actuación de los poderes públicos debe ir dirigida a garantizar el acceso a los derechos básicos que les corresponden para satisfacer su dignidad, para lo cual parece necesario, antes que nada:

Asegurar canales de migración donde no se vulneren los derechos humanos de las personas del sur global. Y adoptar una política migratoria que permita a las personas extranjeras el pleno desarrollo de su personalidad con las garantías previstas en el Estado de derecho para los ciudadanos nacionales.

En este sentido, Juliano (2004) plantea la necesidad de autorizar la residencia y el trabajo de personas migrantes sin la vinculación a un contrato de trabajo. De otro modo, otorgar derechos civiles a las

\footnotetext{
42 La Agencia ABITS es un servicio municipal adscrito a la Dirección de Feminismos y LGTBI del Área de Derechos de Ciudadanía, Cultura, Participación y Transparencia de la Concejalía de Feminismos y LGTBI del Ayuntamiento de Barcelona. Anualmente elabora un informe con los datos de los diversos proyectos de la agencia para el trabajo sexual que tienen como objetivo primordial atender a mujeres cis y trans que ejercen la prostitución en la ciudad de Barcelona.

El informe se encuentra accesible <https://ajuntament.barcelona.cat/dones/sites/default/files/documentacio/informe abits 2017 es def.pdf> acceso: 23 de noviembre de 2021.

43 El informe de 2010 de la Oficina de las Naciones Unidas contra la Droga y el Delito (UNODC) sobre Trata de personas hacia Europa con fines de explotación sexual donde se concreta que en Europa el $14 \%$ de mujeres que ejercen la prostitución son víctimas de trata
} 
personas solo en la media en que puedan ser rentables al sistema económico vulnera en la práctica los derechos humanos.

Sobre la modificación de las políticas migratorias y la necesidad de establecer canales de migración seguros, Carolina Villacampa ${ }^{44}$ se hace eco del informe emitido por el Grupo de Expertos en Trata de Seres Humanos de la Unión Europea en 2004 (refrendado en 2010), donde en materia de prevención se recomienda «incidir en las causas de fondo de la trata, modificando las actuales políticas económicas, incrementar las oportunidades de migración legal y fomentar la cooperación de los Estados destino con los de origen de las personas tratadas».

En segundo lugar, es vital descriminalizar la prestación de servicios sexuales mediante la modificación del marco legislativo que elimine cualquier tipo penal relativo al trabajo sexual y la desvinculación de los conceptos de trata con fines de explotación sexual y la prostitución. María Luisa Maqueda ${ }^{45}$ propone definir la prostitución como «la prestación voluntaria y negociada de servicios sexuales remunerados», de lo que cabe inferir que «la prestación coercitiva de servicios sexuales no es prostitución». En otras palabras, la autodeterminación sexual debería ser respetada sin enfrentarla a una moralidad definida por cuerpos legislativos preconstitucionales.

Algunos tribunales españoles han acogido esta idea de la autodeterminación sexual, como la sentencia de la Sala de lo Social de la Audiencia Nacional 104/2003, de 23 de Diciembre ${ }^{46}$, que admitió la licitud de la prostitución ejercida por cuenta propia; y posteriormente la sentencia de la Sala Penal del Tribunal Supremo 425/2009, de 14 de abril 47 , donde se ha afirmado «que la cuestión de la prostitución voluntaria, bien por cuenta propia o dependiendo de un tercero que establece las condiciones de trabajo que no conculquen los derechos de los trabajadores, no puede solventarse con enfoques morales o concepciones ético-sociológicas ya que afecta a aspectos de la voluntad que no puede ser coartados por el derecho» 48 .

Por último, pero sin duda el primer paso a llevar a cabo en la práctica sería aceptar a las trabajadoras sexuales como sujetos políticos con capacidad de agencia e incluirlas en la toma de decisiones en torno al trabajo sexual. Así lo reclaman las trabajadoras sexuales de Barcelona cuando exigen: el reconocimiento de las trabajadoras

\footnotetext{
${ }^{44}$ Carolina Villacampa, 'Prohibicionismo suave para abordar el trabajo sexual' [2020] Relies <https://www.upo.es/revistas/index.php/relies/article/view/4992> acceso el 23 de noviembre de 2021.

45 Ibid 5.

46 Sentencia 104/2003 [2003] AN Sala de lo social.

47 Sentencia 425/2009 [2009] TS Sala penal.

48 María Luisa Maqueda Abreu, 'La prostitución: el pecado de las mujeres' (2017) Cuadernos Electrónicos de Filosofía del Derecho $<$ https://ojs.uv.es/index.php/CEFD/article/view/9791> acceso el 23 de noviembre de 2021.
} 
sexuales como ciudadanas de pleno derecho teniendo en cuenta nuestra voz en los espacios de participación política y social. Para ello, se debería reforzar nuestra presencia en espacios de participación ciudadana relacionados con las políticas públicas que nos afectan, y por el otro, se nos debería tener en cuenta como parte interesada en espacios de mediación sobre los temas relacionados con la oferta del trabajo sexual en el espacio público ${ }^{49}$.

La posición proderechos 50 no es la mayoritaria dentro del movimiento feminista español, ni como se ha visto, dentro del feminismo institucional, pero la de este trabajo no es la única voz crítica, junto con las trabajadoras sexuales hay muchas aliadas/os reclamando que se escuche a las damnificadas como requisito indispensable en el abordaje del trabajo sexual.

Sin embargo, reconocer a las trabajadoras sexuales fuera del papel de víctimas creado en el imaginario colectivo requiere hacer un ejercicio previo de destierro de los juicios y valoraciones interiorizados y abordar el trabajo sexual con el menor prejuicio posible para no caer en posiciones condescendientes, clasistas y victimistas. Es necesario, además, desarrollar un debate sano dentro del feminismo que reconozca a las trabajadoras sexuales como sujetos de este.

Actualmente las posiciones abolicionistas se han tornado violentas y parece imposible un dialogo entre ambas posturas. Se les niega la identidad rechazando el uso del término trabajadora sexual e imponiendo el de «prostituidas», o afirmando que ofrecer servicios sexuales por dinero es cobrar por ser violadas, utilizando el lenguaje y el debate para agredir a las trabajadoras sexuales. Actualmente se está dando una desviación de la doctrina abolicionista hacía el movimiento denominado SWERF «Sex Worker Exclusionary Radical Feminist» 51 (posición que defiende que las mujeres que ofrecen servicios sexuales no pueden ser incluidas dentro del feminismo) también llamado neoabolicionismo con posturas muy cercanas a consignas fascistas que niegan la identidad y la experiencia propia de este colectivo de mujeres

\footnotetext{
49 Ibid 15.

${ }^{50}$ El movimiento proderechos está formados por colectivos de trabajadoras sexuales y aliadas que promulgan la descriminalización del trabajo sexual y la lucha por los derechos humanos de las trabajadoras sexuales. En España el movimiento de trabajadoras sexuales nació más tarde que en otros países europeos, con organizaciones como el Colectivo Hetaira y La Asociación Libre de Mujeres de Alterne. Actualmente están trabajando con este objetivo: la Asociación de Trabajadoras Sexuales (AFEMTRAS), el colectivo de Ayuda a trabajadoras del Sexo (CATS), el Colectivo de Prostitutas de Sevilla (CPS), las Putas libertarias del Raval, la Asociación de profesionales del sexo (Aprosex) y el Colectivo Caye. Esta organización ha dado lugar al nacimiento del sindicato de Organización de Trabajadoras Sexual (OTRAS), la sección sindical de trabajadoras sexuales dentro de la Intersindical Alternativa de Cataluña y la unión sindical de Trabajo Sexual (USTS).

51 Más información sobre este movimiento se puede encontrar en: <https://www.dailydot.com/irl/swerf/>
} 
y utilizan mecanismos violentos para silenciar y acosar a las trabajadoras sexuales.

Por lo que parece urgente redefinir las posiciones sobre el trabajo sexual y hacer un ejercicio de profunda reflexión dentro del movimiento feminista.

\section{6.- BIBLIOGRAFÍA}

\section{1.- Jurisprudencia}

Sentencia 104/2003 [2003] AN Sala de lo Social. Sentencia 174/2018 [2018] AN Sala de lo Social. Sentencia 425/2009 [2009] TS Sala Penal.

\section{2.- Legislación}

Convenio para la represión de la trata de personas y de la explotación de la prostitución ajena (adoptado el 2 de diciembre de 1949, entrada en vigor el 25 de julio de 1951).

Pacto Internacional de Derechos Civiles y Políticos (adoptado el 16 de diciembre de 1966, entrada en vigor el 23 de marzo de 1976).

Carta de Derechos Fundamentales de la Unión Europea (adoptada el 7 de diciembre de 2000, ratificado el 13 de diciembre de 2007).

Ley Orgánica 4/2000, de 11 de enero, sobre derechos y libertades de los extranjeros en España y su integración social.

Ley Orgánica 4/2015, de 30 de marzo, de protección de la seguridad ciudadana.

Ley 10/1995, de 23 de noviembre, del Código Penal.

Reglamento de la Ley Orgánica 4/2000, sobre derechos y libertadoes de los extranjeros en España y su integración social, aprobado por Real Decreto 557/2011, de 20 de abril.

Real Decreto 240/2007, de 16 de febrero, sobre entrada, libre circulación y residencia en España de ciudadanos de los Estados miembros de la Unión Europea y de otros Estados parte en el Acuerdo sobre el Espacio Económico Europeo.

Decreto 217/2002, de 1 de agosto, por el que se regulan los locales de pública concurrencia donde se ejerce la prostitución.

Orden PRE/335/2003 donde se regulan los requisitos que han de cumplir los locales de pública concurrencia en los que se ejerce la prostitución.

\section{3.- Otros recursos}

Agustín LM 'La industria del sexo, los migrantes y la familia europea' [2005] Cuadernos

Pagu <https://www.researchgate.net/journal/Cadernos-Pagu-01048333> acceso el 23 de noviembre de 2021. 
Arella C y otros, Una aproximación a la vulneración de los derechos humanos de las trabajadoras sexuales (Observatori del Sistema Penal I els Drets Humans 2006).

EDIS S.A. Realidad social de las mujeres sin techo, prostitutas, ex reclusas y drogodependientas en España (Instituto de la mujer 2004)

Guasch O y Lizardo E, Chaperos. Precariado y prostitución homosexual (Bellaterra 2017).

Heim D, 'PROSTITUCIÓN Y DERECHOS HUMANOS' [2011] Cuadernos Electrónicos de Filosofía del Derecho < https://ojs.uv.es/index.php/CEFD/article/view/716/472> acceso 23 de noviembre de 2021.

Juliano D, 'El trabajo sexual en la mira: polémicas y estereotipos' [2005] Cuadernos Pagu < https://www.scielo.br/j/cpa/a/yf64fKYh9m5XKmLp9wxrCqp/abs tract/?lang=es $>$ acceso el 23 de noviembre de 2021.

Maqueda ML, Prostitución, Feminismos y Derecho Penal (Comares 2009).

Maqueda ML, 'La prostitución: el pecado de las mujeres' [2017] Cuadernos Electrónicos de Filosofía del Derecho < https://ojs.uv.es/index.php/CEFD/article/view/9791>.

Mansilla $\mathrm{P}$, Informe cualitativo sobre las percepciones, demandas $y$ propuestas de las trabajadoras del sexo que contactan con clientela en el espacio público de la ciudad de Barcelona (Putas\&alianzas 2016).

Mestre RM y López M, Trabajo sexual: reconocer derechos (Ediciones La Burbuja 2006).

Oso $L$ y Ulloa $M$, 'Tráfico e inmigración femenina desde la voz de las mujeres migrantes' en Bonelli E y Ulloa M (coords.) Tráfico e inmigración de mujeres en España. Colombianas y ecuatoriana en los servicios domésticos y sexuales (ACSUR-Las Segovias 2001).

Poyatos G, Prostitución como trabajo autónomo (Bosch 2009).

Redlich R, 'Desmontando el abolicionismo del 80\%' (youtube, 2018) < https://youtu.be/G85BXqUQ87E> acceso 23 de noviembre de 2021.

Villacampa C, 'Prohibicionismo suave para abordar el trabajo sexual' [2020] Relies < https://www.upo.es/revistas/index.php/relies/article/view/4992 $>$ acceso el 23 de noviembre de 2021. 